\title{
The Effect of Short-Term Resistance Training on Heart of Nonathletic Healthy Male Students by Echocardiograph
}

\author{
Hassan Gharayagh Zandi, ${ }^{1}$ seyyedmostafa Tayybi, ${ }^{2}$ Hasan Abdi, ${ }^{3}$ \\ Hassan Masoumi ${ }^{4}$ \\ 1Assistant professor of sport psychology, faculty of physical education, University of Tehran, Iran \\ 2-3Assistant professor Islamic Azad University of sharoud Iran \\ 4Assistant professor Islamic Azad University of ChaloosIran
}

\begin{abstract}
Background and Purpose: Resistance Training (RT) is known as weight or strength training. In response to this kind of training, both skeletal and cardiac muscles adapt. The purpose of the present study was to determine of effect of Short-term Resistance Training on Left Ventricular Structure of Nonathletic Healthy Male Students by Echocardiography.

Methods and Materials: this quasi-experimental study involved thirty volunteer participants with an age range of 19to 25 years Mean $\pm S D: 21.8 \pm 1$.62.They were randomly divided into two groups of 15 (resistance training and control).Training program was performed 3 times a week for 12 weeks followed by 10 station with 50\%. To 80\%. With one repletion maximum (IRM).M and B-mode echocardiograph variable were measured at rest. The data were analyzed using dependant $t$-test and independent $t$-test.

Result: Training caused a significant increase in the mean absolute and relative values of left ventricular mass $(L V M)$, left ventricular end -diastolic dimensions (LVEDd), end-diastolic inter ventricular septum thickness $(E D I V T)(P=0.000)$, and left ventricular posterior wall thickness end-diastolic (LVPWd)in the training group ( $p=$ $0.044, p=0.00)$

Absolute and relative values of left ventricular end -systolic dimension (LVESd) decreased significantly after training $(P=0.001, P=0.018)$. Between groups comparison of absolute and relative values of $L V M, E D I V T$ and $L V P W d$ in the training group showed a significant increases as compared with the control group $(P=0.000)$ :also there was a significant increase in the absolute value of LVEDd $(P=0.002)$.

Conclusion: Modification of resistance training can induce changes in the left ventricular structure of nonathletes.
\end{abstract}

Key Words: Resistance Training; circuit weight Training; heart; left ventricle

\section{Introduction}

Resistance training (RT) is known as weight or strength training, in response to which both skeletal and cardiac muscles adapt (1). Strength training increases the production of end-systolic proteins and muscular hypertrophy- especially in fast twitch strings- that may be along with a decrease in volume density of mitochondories (2-4). Also, strength training increases muscular strength $(5,6)$ and non-fat mass and decreases fat percents of the body $(5,7,8)$. This form of training is accompanied with an intense and severe increase of systolic or after load blood pressure (9) that may be a powerful stimulator for increasing the thickness and the mass of the left ventricle (10). The increase of the thickness of the septum due to the overload of the pressure produced in resistance training is mainly due to the increase of the cross section of muscular cells (11). When strength training is done, the pressure inside the chest also increases (12). Due to the phenomenon Valsalva maneuver, the drop of the vein blood recession increases significantly and as a result, the heart pulse and the average artery blood pressure increase (13). In those athletes participating in intense isometric, strength or static training (anaerobic, strength and power training), concentric hypertrophy of the left ventricle is created (14). This hypertrophy is identified by an increase in the thickness of heart septum and creates no changes in the diameter of the hole of the left ventricle in diastole (1).

From the past to the present various methods are used in heart studies that the most important of them include radiography, electrocardiography, echocardiography and magnetic resonance imaging. The best method is noninvasive evaluation of echocardiography that provides many information about structural and performance adaptation in the heart of healthy people $(15,16)$.

In past studies, the effects of resistance training on the heart of healthy people are examined (1, 18-30). In some of the studies, it is stated that resistance trainings increase interventricular septum thickness, left ventricular posterior wall and Left Ventricular Mass Index (LVEDd) (17, 18, 20, 21, 31-33). However, some studies have also shown that long- and short-term resistance trainings can't have an effect on cardiac indexes 
including LVEDd, interventricular septum thickness, left ventricular posterior wall thickness, LVM, systolic performance and fractional shortening $(24,26,28)$.

Although the effect of resistance training on skeletal muscles is known (26), the effect of these trainings on cardiovascular adaptations is inconsistent $(28,35,36)$. However, several studies have examined the effects of short-term resistance training on the structure of the left ventricle $(14,17,19,26-28,30)$. But no study is done about the effect of short-term resistance training on the structure of the left ventricle of Iranian nonathletic males. Therefore other researches are necessary to examine the independent effects of these types of trainings on the structural properties of the left ventricle of these people.

The purpose of the present research is to determine the effect of short-term resistance training on the structure of the left ventricle of nonathletic healthy male students using echocardiography. In the present study, the researcher tried to make the nature of training program similar to the strength-endurance training through changing the program of weight training and modifying in resting intervals (reducing rests between training stations) and increasing the number of training stations, and to examine the effect of such a program on the structural changes of the left ventricle of nonathletic healthy students.

\section{Methods and materials}

The present study is a semi-empirical one with a pre-test or post-test design. Its statistical society is all of the male students of the faculty of accounting, Islamic Azad University, Central Tehran branch, between 18 to 25 years old that had adopted the course physical education 2 . The volume of the sample was 30 non-athletic healthy students with the average age $21.80 \pm 1.62$ years old, the length $175.63 \pm 3.73 \mathrm{~cm}$ and the weight $70.78 \pm 3.72 \mathrm{~kg}$, that participated voluntarily in the research. The criteria of choosing the participants were having a general health and a perfect cardiovascular health (with the confirmation of the physician), no drug abuse, no sport supplementary, not smoking and not doing regular professional exercises and having the age range 18 to 25 years old (the questionnaire of medical and sport information). Then, among the volunteer participants, those not being healthy were omitted from the research and the remaining was randomly grouped into two resistances and control groups each containing 15 people. Before conducting the study, since the subjects had no experience of working with weights and to prevent from damages during trainings with devices, they were taught about the details of the training program, the correct way of trainings and performing the tests. The subjects also filled the satisfaction form of participating in the tests and trainings.

The training program: the training program was performed for 12 weeks, each including 3 sessions, in 10 stations (foot pressing, chest pressing, scot, forward top shoulder, fore feet, shoveling, back feet, fore arms, shins and back arms) in three to five rounds with the intensity 50 to $80 \%$ of a maximum repletion. At the beginning of the trainings and in the fourth and the eighth weeks of the test, the maximum strength was calculated by the following relation (37):

One maximum repetition= times $(\mathrm{kg}) / 1-(0.02 \times$ the number of repetitions $)$

For calculating the maximum strength, the subjects chose a weight through the initial evaluation of their maximum strength and performed it to the limit of over-weariness. Then, putting the value of the weight and the number of repetitions in the related formula, the maximum strength was evaluated. In performing this test, the number of repeating weight lifting for any subject in any test must be not more than 8 repetitions and less than 3 repetitions. The time of activity in any station was considered 30 seconds, the resting time between stations was considered 15 seconds and the resting time between any rounds of training was considered 90 seconds. The overload principle was designed so that in fourth, eighth and twelfth weeks, load reduction was applied. The program of any session of training included 10 minutes warming (public and specialty warming) and then performing the station movements and then 10 minutes cooling. All movements of the training were performed circularly using halter, weights and body building equipments.

Measuring personal characteristics of the subjects: the age was measured in terms of years through asking the subjects. Measuring the height was done in terms of $\mathrm{cm}$ (with the accuracy $1 \mathrm{~mm}$ ) and the weight of the body was measured in terms of $\mathrm{kg}$ (with the accuracy $0.1 \mathrm{~g}$ ) using the medical scale SECA (model 220 made by Germany) that was equipped with a height meter. Body mass index (BMI) was calculated measuring the weight in $\mathrm{kg}$ and the length $m^{2}(38)$ :

Body surface area (BSA) was calculated using Mostellerfomula (39):

$\mathrm{BSA}=($ length $(\mathrm{cm}) \times$ weight $(\mathrm{kg}) / 3600) \frac{1}{2}$

Measuring structural variables of the left ventricle: measuring the structural variables of the left ventricle was done in the room of echocardiography by a physician with a cardiovascular specialization using 
the echocardiography device (P8000, General Electric factory, s,p.d. company of the U.S.A.) and a probe $3.5 \mathrm{~Hz}$ with a one- and two- dimensional method in a standard manner from the view of length section beside sternum according to the method of the American Society of echocardiography at rest (40). While the subjects lay at the distance of $50 \mathrm{~cm}$ from the echocardiograph device, on the left side with the angle $90^{\circ}$ to the earth, the left ventricular end-diastolic dimensions (LVEDd), the end-diastolic interventricular Septum thickness (EDIVT) and the left ventricular posterior wall thickness (LVPWd) at the beginning of QRS complex of the electrocardiogram and the left ventricular end-systolic dimensions (LVESd), the end-systolic inter ventricular Septum thickness (ESIVT) and the left ventricular posterior wall thickness end-systolic at the beginning of the $T$ wave of the electrocardiogram were measured (17). After measuring the dimensions and the thicknesses, LVM was calculated using Devereux Formula (41):

\section{$\mathrm{LVM}=(0.8)\left[(1.04)\left(\mathrm{LVEDd}_{+} \mathrm{LVPWd}+\mathrm{EDIVT}^{3}\right)^{3}-\mathrm{LVEDd}^{3}\right]+0.6 \mathrm{~g}$}

Where LVM is left ventricle mass, LVEDd is the left ventricular end-diastolic dimensions, LVPWd is the left ventricular posterior wall thickness end-systolic, EDIVT is the end-diastolic inter ventricular Septum thickness and $\mathrm{g}$ is gram. All measurements were done three times for all subjects and the average was recorded three times. Then, the relative values of all structural variables were calculated based on the body surface area to compare the subjects more exactly.

Statistical methods: the descriptive statistics was used for calculating the measure of central tendency (average) and distribution (standard deviation). For testing the hypotheses of the research, the correlated T-test was used for comparing the pre-test and the post-test mean of any group and the independent T-test was used for comparing the differences of the means of the test group and the control group in pre- and post-tests. All tests were done at the alpha level 5\% and using SPSS statistical package, the duplicate 16.

\section{Findings}

The subjects of both groups did not show a significant difference in personal characteristics and the absolute and the relative values of the structural features of the left ventricle which shows the homogeneity of the subjects (tables 1 and 2). In the post-test compared to the pre-test, LVM $(\mathrm{P}<0.000)$, LVEDd $(\mathrm{P}<0.000)$, EDIVT $(\mathrm{P}<0.000)$, ESIVT $(\mathrm{P}<0.0000)$, LVPWd $(\mathrm{P}<0.000)$ and LVPWs $(\mathrm{P}<0.044)$ absolutely and significantly increased in the training group after the activity (compared to before the activity), but LVESd had a significant decrease $(\mathrm{P}<0.018)$. When the structural variables of the left ventricle of the subjects of the training group were calculated relatively and based on the body surface area in the post-test compared to the pre-test, LVM $(\mathrm{P}<0.000)$, LVEDd $(\mathrm{P}<0.000)$, LVESd $(\mathrm{P}<0.001)$, EDIVT $(\mathrm{P}<0.000)$, LVPWd $(\mathrm{P}<0.000)$ had significant variations (table 3 ). In the post-test, when the structural variables of the left ventricle of the two groups were compared absolutely, LVM $(\mathrm{P}<0.000)$, LVEDd $(\mathrm{P}<0.002)$, EDIVT $(\mathrm{P}<0.000)$ and LVPWd $(\mathrm{P}<0.000)$ increased significantly in the training group compared to the control group. When we compared relatively the structural variables of the left ventricle in the post-test based on the body surface area, only LVM ( $<<0.000)$, EDIVT $(\mathrm{P}<0.000)$ and LVPWd $(\mathrm{P}<0.000)$ showed a significant variation (table 4$)$.

Table 1: personal characteristics of the participants of the test and control groups

\begin{tabular}{|l|l|l|}
\hline Variable/group & $\begin{array}{l}\text { Circuit training group with weights } \\
\text { (numbers 15) } \\
\text { Standard deviation } \pm \text { mean }\end{array}$ & $\begin{array}{l}\text { Control group (numbers 15) } \\
\text { Standard deviation } \pm \text { mean }\end{array}$ \\
\hline Age $($ years) & $21.60 \pm 1.84$ & $22 \pm 1.41$ \\
\hline Height $(\mathrm{cm})$ & $176.80 \pm 3.60$ & $174.46 \pm 3.60$ \\
\hline Weight $(\mathrm{kg})$ & $71.38 \pm 3.85$ & $70.18 \pm 3.62$ \\
\hline Body mass index $\left(m^{2} / \mathrm{kg}\right)$ & $22.84 \pm 0.57$ & $23.04 \pm 0.52$ \\
\hline Body surface area $\left(m^{2}\right)$ & $1.86 \pm 0.07$ & $1.85 \pm 0.07$ \\
\hline
\end{tabular}


Table 2: the comparison between absolute and relative values and structural features of the left ventricle in the pre-test of the test group

\begin{tabular}{|c|c|c|c|c|}
\hline \multirow[t]{2}{*}{ Variable/group } & \multicolumn{2}{|c|}{$\begin{array}{l}\text { The comparison of the pre-tests means of } \\
\text { the groups } \\
\text { Standard value } \pm \text { mean }\end{array}$} & \multirow[t]{2}{*}{$\mathrm{T}$ value } & \multirow[t]{2}{*}{$\mathrm{P}$ value } \\
\hline & Test group & Control group & & \\
\hline LVM (gr) & $99 / 09 \pm 16 / 72$ & $101 / 52 \pm 19 / 91$ &.$- / 362$ &.$/ 720$ \\
\hline $\mathrm{LVM} / \mathrm{BSA}\left(\mathrm{gr} / m^{2}\right)$ & $53 / 44 \pm 9 / 80$ & $54 / 63 \pm 9 / 62$ &.$- / 335$ &.$/ 740$ \\
\hline LVEDd(mm)* & $46 / 20 \pm 3 / 36$ & $46 / 25 \pm 3 / 32$ &.$- / 038$ &.$/ 970$ \\
\hline $\mathrm{LVEDd} / \mathrm{BSA}\left(\mathrm{mm} / m^{2}\right)^{* *}$ & $24 / 78 \pm 2 / 20$ & $24 / 95 \pm 1 / 66$ &.$- / 236$ &.$/ 815$ \\
\hline LVEDs $(\mathrm{mm})$ & $28 / 89 \pm 2 / 93$ & $28 / 53 \pm 2 / 69$ &.$/ 348$ &.$/ 730$ \\
\hline $\mathrm{LVEDs} / \mathrm{BSA}\left(\mathrm{mm} / \mathrm{m}^{2}\right)$ & $15 / 45 \pm 1 / 67$ & $15 / 42 \pm 1 / 31$ &.$/ .61$ &.$/ 952$ \\
\hline EDIVT(mm) & $7 / 26 \pm . / 58$ & $7 / 16 \pm . / 73$ &.$/ 441$ &.$/ 662$ \\
\hline EDIVT/BSA $\left(\mathrm{mm} / m^{2}\right)$ & $3 / 90 \pm . / 33$ & $3 / 86 \pm 0 / 38$ &.$/ 330$ &.$/ 744$ \\
\hline ESIVT(mm) & $11 / 58 \pm . / 89$ & $11 / 39 \pm . / 91$ &.$/ 568$ &.$/ 874$ \\
\hline $\operatorname{ESIVT} / \mathrm{BSA}\left(\mathrm{mm} / m^{2}\right)$ & $6 / 21 \pm . / 62$ & $6 / 15 \pm . / 58$ &.$/ 282$ &.$/ 780$ \\
\hline $\mathrm{LVPWd}(\mathrm{mm})$ & $6 / 35 \pm . / 53$ & $6 / 42 \pm . / 54$ &.$- / 372$ &.$/ 712$ \\
\hline $\mathrm{LVPWd} / \mathrm{BSA}\left(\mathrm{mm} / m^{2}\right)$ & $3 / 40 \pm . / 29$ & $3 / 46 \pm . / 29$ &.$- / 613$ & .1545 \\
\hline LVPWs(mm) & $11 / 29 \pm . / 73$ & $11 / 30 \pm . / 70$ &.$- / .51$ & .1960 \\
\hline $\mathrm{LVPW} / \mathrm{BSA}\left(\mathrm{mm} / m^{2}\right)$ & $6 / .5 \pm . / 53$ & $6 / 10 \pm . / 47$ &.$- / 255$ & $. / 801 \pm$ \\
\hline
\end{tabular}

Absolute value, **relative values, left ventricle mass (LVM), gram (gr), left vetriclular end-diastolic dimensions (LVEDd), millimeter ( $\mathrm{mm}$ ), Left ventricular end-systolic dimensions (LVESd), end-diastolic interventricular Septum thickness (ESIVT), left ventricular posterior wall thickness (LVPWd), left ventricular posterior wall thickness end-systolic (L body surface area (BSA), millimeters to square meters $\left(\mathrm{mm} / \mathrm{m}^{2}\right.$ ), mean (M), standard deviation (SD). VPWs),

Table 3: the absolute and the relative values of the structural features of the left ventricle in the post-test compared to the pre-test

\begin{tabular}{|c|c|c|c|c|c|c|}
\hline \multirow[t]{2}{*}{ Variable/ group } & \multicolumn{2}{|c|}{$\begin{array}{l}\text { Test group } \\
\text { Standard deviation } \pm \text { mean }\end{array}$} & \multirow[t]{2}{*}{$\mathrm{P}$ va } & \multicolumn{2}{|c|}{$\begin{array}{l}\text { Control group } \\
\text { Standard deviation } \pm \text { mean }\end{array}$} & \multirow[t]{2}{*}{$\begin{array}{l}\mathrm{P} \\
\text { va }\end{array}$} \\
\hline & Pre-test & Post-test & & Pre-test & Post-test & \\
\hline LVM (gr)*** & $99 / 09 \pm 16 / 7$ & $137 \pm 16 / 8$ &.$/ . * *$ & $101 / 5219 / 91$ & $100 / 815 / 47$ &.$/ 69$ \\
\hline $\mathrm{LVM} / \mathrm{BSA}\left(\operatorname{gr} m^{2}\right) * * * *$ & $53 / 44 \pm 9 / 80$ & $72 / 20 \pm 8 / 7$ &.$/ . . * *$ & $54 / 63 \pm 9 / 62$ & $54 / 56 \pm 7 / 71$ &.$/ 63$ \\
\hline LVEDd(mm) & $46 / 20 \pm 3 / 36$ & $49 / 742 / 70$ &.$/ . * *$ & $46 / 25 \pm 3 / 32$ & $46 / 11 \pm 3 / 15$ &.$/ 48$ \\
\hline LVEDs/BSA $\left(\mathrm{mm} / m^{2}\right)$ & $24 / 78 \pm 2 / 20$ & $26 / 16 \pm 1 / 8$ &.$/ . * *$ & $24 / 95 \pm 1 / 66$ & $25 \pm 1 / 70$ &.$/ 81$ \\
\hline LVEDs $(\mathrm{mm})$ & $28 / 89 \pm 2 / 93$ & $28 / 33 \pm 3 / 3$ &.$/ .1^{*}$ & $28 / 53 \pm 2 / 69$ & $28 / 68 \pm 2 / 53$ &.$/ 38$ \\
\hline LVEDs/BSA $\left(\mathrm{mm} / m^{2}\right)$ & $15 / 45 \pm 1 / 67$ & $14 / 90 \pm 1 / 9$ &.$/ .1^{*}$ & $15 / 42 \pm 1 / 31$ & $15 / 55 \pm 1 / 37$ &.$/ 34$ \\
\hline EDIVT(mm) & $7 / 26 \pm .158$ & $8 / 48 \pm . / 58$ &.$/ . * *$ & $7 / 16 \pm . / 73$ & $7 / 23 \pm . / 69$ &.$/ 47$ \\
\hline EDIVT/BSA $\left(\mathrm{mm} / m^{2}\right)$ & $3 / 90 \pm . / 33$ & $4 / 45 . / 29$ &.$/ . * *$ & $3 / 86 \pm . / 38$ & $3 / 91 \pm . / 34$ &.$/ 34$ \\
\hline $\mathrm{ESIVT}(\mathrm{mm})$ & $11 / 58 \pm . / 89$ & $11 / 84 \pm . / 85$ &.$/ . * *$ & $11 / 39 \pm . / 91$ & $11 / 52 \pm 11 / 9$ &.$/ 37$ \\
\hline $\operatorname{ESIVT} / \mathrm{BSA}\left(\mathrm{mm} / m^{2}\right)$ & $6 / 21 \pm . / 62$ & $6 / 22 \pm . / 57$ &.$/ 45$ & $6 / 15 \pm . / 58$ & $6 / 24 \pm . / 56$ &.$/ 22$ \\
\hline LVPWd(mm) & $6 / 35 \pm . / 53$ & $7 / 37 \pm . / 63$ &...$* *$ & $6 / 42 \pm . / 54$ & $6 / 48 \pm . / 51$ &.$/ 59$ \\
\hline $\mathrm{LVPWd} / \mathrm{BSA}\left(\mathrm{mm} / m^{2}\right)$ & $3 / 40 \pm . / 29$ & $3 / 87 \pm . / 31$ &.$/ . . * *$ & $3 / 46 \pm . / 29$ & $3 / 51 \pm . / 28$ &.$/ 42$ \\
\hline LVPWs(mm) & $11 / 29 \pm . / 73$ & $11 / 48 \pm . / 91$ & $1.4 * *$ & $11 / 30 \pm . / 70$ & $11 / 28 \pm / 68$ & .194 \\
\hline $\mathrm{LVPWs} / \mathrm{BSA}\left(\mathrm{mm} / m^{2}\right)$ & $6 / .5 \pm . / 53$ & $6 / .4 \pm . / 60$ &.$/ 55$ & $6 / 10 \pm . / 47$ & $6 / 11 \pm . / 47$ &.$/ 71$ \\
\hline
\end{tabular}

Significant compared to the mean before the activity $(\mathrm{P}<0.05), * *$ significant compared to the mean before the activity $(\mathrm{P}<0.01), * * *$ absolute values, $* * * *$ relative values. 
Table 4: the comparison between the absolute and the relative values of the mean difference of the structural features of the left ventricle in the post-test

\begin{tabular}{|c|c|c|c|c|}
\hline \multirow[t]{2}{*}{ Variable/group } & \multicolumn{2}{|c|}{$\begin{array}{l}\text { The comparison of the post- test means of } \\
\text { the groups } \\
\text { Standard deviation } \pm \text { mean }\end{array}$} & \multirow[t]{2}{*}{$\mathrm{T}$ value } & \multirow[t]{2}{*}{$P$ value } \\
\hline & Test group & Control group & & \\
\hline LVM(gr)* & $137 / 43 \quad 16 / 88$ & $100 / 8015 / 47$ & $6 / 194$ &.$\ldots * *$ \\
\hline $\mathrm{LVM} / \mathrm{BSA}\left(\mathrm{gr} / m^{2}\right)^{* *}$ & $72 / 208 / 74$ & $54 / 567 / 71$ & $5 / 860$ &.$/ \ldots * *$ \\
\hline LVEDd(mm) & $49 / 742 / 70$ & $46 / 113 / 15$ & $3 / 366$ &.$/ .2 * *$ \\
\hline LVEDd/BSA $\left(\mathrm{mm} / m^{2}\right)$ & $26 / 161 / 81$ & $251 / 70$ & $-1 / .68$ &.$/ 295$ \\
\hline LVEDs $(\mathrm{mm})$ & $28 / 333 / 33$ & $28 / 682 / 53$ & $-/ 328$ &.$/ 745$ \\
\hline $\mathrm{LVEDs} / \mathrm{BSA}\left(\mathrm{mm} / m^{2}\right)$ & $14 / 901 / 89$ & $15 / 551 / 37$ & $1 / 8.4$ &.$/ .82$ \\
\hline EDIVT(mm) & $8 / 48 . / 58$ & $7 / 23 . / 69$ & $5 / 328$ &.$/ \ldots * *$ \\
\hline $\operatorname{EDIVT} / \mathrm{BSA}\left(\mathrm{mm} / m^{2}\right)$ & $4 / 45 . / 29$ & $3 / 91 . / 34$ & $4 / 577$ &.$\ldots * *$ \\
\hline ESIVT(mm) & $11 / 84 . / 85$ & $11 / 5211 / 96$ & .968 &.$/ 341$ \\
\hline $\operatorname{ESIVT} / \mathrm{BSA}\left(\mathrm{mm} / m^{2}\right)$ & $6 / 22 . / 57$ & $6 / 24 . / 56$ &.$- / .74$ &.$/ 942$ \\
\hline LVPWd (mm) & $7 / 37 . / 63$ & $6 / 48 . / 51$ & $4 / 2.4$ &.$/ \ldots * *$ \\
\hline $\mathrm{LVPWd} / \mathrm{BSA}\left(\mathrm{mm} / m^{2}\right)$ & $3 / 87 . / 31$ & $3 / 51 . / 28$ & $3 / 310$ &.$/ .3^{* *}$ \\
\hline LVPWs $(\mathrm{mm})$ & $11 / 48 . / 91$ & $11 / 28 . / 68$ &.$/ 700$ & .1490 \\
\hline LVPWs/BSA $\left(\mathrm{mm} / m^{2}\right)$ & $6 / .4 . / 60$ & $61 / 11 . / 47$ &.$- / 392$ &.$/ 698$ \\
\hline
\end{tabular}

significant at the level $(\mathrm{P}<0.01), *$ absolute values, $* * *$ relative values

\section{Conclusion}

The purpose of the present study was to determine the effect of short-term resistance training on the structure of the left ventricle using echocardiography. The important finding of our research was that the absolute values of LVM, LVEDd, EDIVT, ESIVT, LVPWd and LVPWs increased significantly after 12 weeks training compared to before training. LVESd decreased significantly at this period. When the variables were calculated relatively based on the body surface area, LVM, LVEDd, EDIVT and LVPWd increased after 12 weeks training; at this period, LVESd had a relatively significant decrease.

Maybe the increase in the values of these variables in the post-test of the training group compared to the pre-test is due to the special resistance training method that was used in this study, because the special type of the resistance training is one of the factors effecting on the cardiac variables (25).

The increase in the volume of the left ventricle hole shows the volume overload on the heart that is the same as what happens in endurance athletes (42). Most researches conducted about short-term resistance trainings and the studies done on highly resistantly trained males showed that doing strength trainings have a low effect or no effect on the absolute value of the internal dimensions of the left ventricle that are considered as an index of the heart hole measure $(19,43)$. This overload is a function of venous recession, volume of the ventricle and the decrease of heart sequence(44).the increase of LVEDd was probably due to the decrease in the resting intervals between training stations and the volume of training (the number of training stations) in any round of circuit weight trainings, as a result of which the cardiovascular system faced with the volume overload pattern in addition to the pressure overload, that probably increased the LVEDd in the present research. In the researches conducted by Kanakis and Hickson (1980), Haykowsky et al (2000) and Levinger et al (2005), it was found out that LVEDd does not change after resistance trainings that is inconsistent with the present research $(17,23,26,28)$. Maybe the cause of inconsistency is the special type of resistance training that was used in the present study, because compared to previous studies, in this study, the number of training stations had increased, while the resting intervals between training stations had reduced and the nature of training program had become somewhat similar to strength-endurance trainings. No previous studies reported an increase in LVEDd after short-term resistance trainings.

Due to cardiac adaptations during long-term exercises, the power of systole increases and the ventricular discharge increases, that decreases the end-systolic volume in the ventricles that finally leads to a decrease in LVESd (31). Maybe the most important cause of variation in LVESd is the increase in systolic power of the heart muscle, so that with its stronger systole, the heart pumps more blood outside of the ventricle and the ventricle reduces the remaining volume and it finally leads to a reduction in LVESd. The increase in the ventricular septum thickness is considered as an adaptation to the increases of blood pressures during strength trainings (43). Probably, circular weight trainings increase the blood pressure to an extent that causes structural adaptations in the heart. Also, the training method may be so that it causes this change in left ventricular wall thicknesses. Maybe, the sensitivity of these variables to this method of resistance training is high and the 
probable cause may be this that the left ventricular wall thickness increases absolutely and relatively in the test group in the post-test compared to the pre-test. In the studies conducted by Kanakis and Hickson (1980), Fleck and Barauna et al (2007) showed that the interventricular Septum thickness and left ventricular posterior wall thickness increase after resistance trainings $(1,17,19)$, that is consistent with the present study. Maybe the cause of consistency is in the nature of resistance trainings, because resistance trainings are the stimulator of increase in ventricular wall thickness. On the other hand, the present study was inconsistent with that of Haykowsky et al (1998) and $(2000)(23,26)$. The cause of this inconsistency is probably related to the age of the subjects, the intensity of the training, the resting interval between trainings rounds and the volume of training. Martin et al (1974) also found out that cardiac variations with resistance training depend on the number of muscles applied in the training and the volume of training (45).

The left ventricular mass increased absolutely and relatively in the test group in the post-test compared to the pre-test. In the comparison between groups in the post-test, this variable increased in the test group compared to the control group. The increase in ventricular mass is the result of increase in the ventricular wall thickness or is produced by an increase in the dimension of the ventricular hole (42). In another research, it was shown that after load increase in resistance athletes increases the thickness and LVM (26) that this increase is probably due to the nature of resistance training that increases the after load and this after load is the stimulator of the increase in the left ventricular mass and thickness (26). In the researches conducted by Kanakis and Hickson (1980), Fleck et al (1988) and Jerry et al (1999), it is shown that LVM increases after resistance trainings that was consistent with the present research $(13,17,19)$. Maybe the cause of consistency is in the nature of resistance trainings, but in the research conducted by Haykowsky et al (2000), it was shown that the left ventricular mass decreases after resistance training that is inconsistent with the present research and the cause of the inconsistency is in the age of the subjects (26). Fredrick et al (2000) believes that aged subjects need a longer time of training pressure for producing structural changes of the left ventricle (46).

In the post-test, when the structural variables of the left ventricle were compared absolutely in both groups, LVM, LVEDd, EDIVT and LVPWd increased significantly in the test group compared to the control group. But when these variables were compared relatively based on the body surface area in the groups, LVM, EDIVT and LVPWd only showed a significant change. The cause of the effect of circuit weight training on the structure of the left ventricle may be probably due to the change of the circuit weight training program and the modifications applied on this training program. A correct planning of the weight training program is usually mixed with the training of the lower limb and upper limb muscular groups that may not be possible in many aerobic activities including walking and biking (47). Evidences show that the effects of resistance trainings depend of the intensity, volume and the resting interval between training rounds $(48,49)$. After circuit weight trainings, the endurance, the strength and the pumping capacity of the heart increase $(50,51)$. The advantage of circuit weight training to the other endurance trainings is that all big muscular groups become active and different muscles are used at different times. Probably in these trainings, two heart adaptation mechanisms seen in endurance and strength trainings are produced, so that in endurance trainings, structural adaptations are produced in the heart due to the increase of the pre-load and in strength trainings, it is produced due to the increase of the after load in the heart.

Generally, according to the results obtained in this research, it seems that circuit weight short-term training can cause structural variations in the left ventricle of the non-athletes through reducing resting intervals between training stations, increasing the number of training stations and using big muscles of the lower and upper limbs and these changes are somewhat similar to those produced in combined trainings. But when we calculate the data relatively based on the body surface area, these changes are slighter and lower.

\section{Reference}

[1]. Barauna VG, Rosa KT, Irigoyen MC, DeOliveiraEM.Effects of resistance training on ventricular function and hypertrophy in a rat model.Clin Med Res. 2007; 5(2): 114-120.

[2]. Eliakim, A, Barstow T, Brasel J, Ajie H, Lee W, Renslo R, et al. Effect of exercise training on energy expenditure, muscle volume, and maximal oxygen uptake in female adolescents. J Pediatr. 1996; 129(4): 537-43.

[3]. McArdel W, Katch D, Katch FI, Victor L. Essentials of exercise physiology. Second edition.Maryland:Lippincott Williams \& Wilkins: 2000.

[4]. Häkkinen K, Pakarinen A, Kraemer WJ, Häkkinen A, Valkeinen H, Alen M. Selective muscle hypertrophy, changes in EMG and force and serum hormones during strength training in older women. J Appl Physiol. 2001; 91(2): 569-80.

[5]. Cullinen K, Caldwell M. Weight training increases fat-free mass and strength in untrained young women. J Am Diet Assoc. 1998; 98(4):414-8.12.

[6]. Binder EF, Yarasheski KE, Steger-May K, Sinacore DR, Brown M, Schechtman KB, et al. Effects of progressive resistance training on body composition in frail older adults: results of a randomized controlled trial. J Gerontol A BiolSci Med Sci. 2005; 60(11): 1425-31.

[7]. Nichols JF, Omizo DK, Peterson KK, Nelson KP. Efficacy of heavy-resistance training for active women over sixty: muscular strength, body composition, and program adherence. J Am Geriatr Soc. 1993; 41(3): 205-10.

[8] Shaw BS, Shaw I. Effect of resistance training on cardio respiratory endurance and coronary artery disease risk. Cardio J S Afr. 2005; 16(5): 256-9.

[9]. MacDougall JD, McKelvie RS, Moroz DE, Sale DG, McCartney N, Buick F. Factors affecting blood pressure during heavy weightlifting and static contractions. J Appl Physiol. 1992; 73(4): 1590-7.

[10]. Colan SD. Mechanics of left ventricular systolic and diastolic function in physiologic hypertrophy of the athlete's heart. CardiolClin. 1997; 15(3): 355-72. 
[11]. Grossman W, Jones D, McLaurin LP. Wall stress and patterns of hypertrophy in the human left ventricle. J Clin Invest. 1975; 56(1): 56-64.

[12]. MacDougall JD, Tuxen D, Sale DG, Moroz JR, Sutton JR. Wall stress and patterns of hypertrophy in the human left ventricle. J Appl Physiol. 1985; 58(2): 785-790.

[13]. Mayo JJ.,Kravitz L. A review of the acute cardiovascular responses to resistance exercise of healthy youngandadults.JSCR. 1999; 13 (1): 90-6.

[14]. Pluim BM, Zwinderman AH, Van der laarse A, Ernst E, Van der wall MD. The athlete's heart: a metaanalysisof cardiac structure and function. Circulation . 1999; 101(3): 366-44.

[15]. Henriksen H, Landelius J, Wesslen L, Arnell H, Kangro T, Jonason T, et al. Echocardiographic right and left ventricular measurement in male elite endurance athletes. Eur Heart J. 1996; 17(7): 1121-8.

[16]. Bjornstad H, Smith G, Storstein L, Meen HD, Hals O. Electrocardiographic and echocardiographic findings in top athletes, athletic students and sedentary controls. Cardiology. 1993; 82(1): 66-74.

[17]. Kanakis C, Hickson RC. Left ventricular responses to a program of lower limb Strength training.Chest.1980; 78(4): 618-21.

[18.] Brown SP, Thompson WR. Standardization indices of cardiac hypertrophy in weight lifters. J Sports Sci. 1987; 5(2): 147-53.

[19]. Fleck SJ. Cardiovascular adaptations to resistance training.MedSci Sports Exerc. 1988; 20(5): S146-51.

[20.] Fleck SJ, Henke C, Wilson W. Cardiac MRI of elite junior Olympic weight lifters. Int J Sports Med. 1989; 10 (5): 329-33.

[21]. Fleck SJ, Pattany PM, Stone MH, Kraemer WJ, Thrush J, Wong K. Magnetic resonance imaging determination of left ventricular mass: Junior Olympic weightlifters. Med Science Sports Exerc. 1993; 25(4): 522-7.

[22]. George KP, Batterham AM, Jones B. Echocardiographic evidence of concentric left ventricular enlargement in female weight lifters. Eur J ApplPhysiolOccup Physiol. 1998; 79(1): 88-92.

[23]. Haykowsky MJ, Gillis R, Quinney HA, Ignaszewski AP, Thompson CR. Left ventricular morphology in elite female resistancetrained athletes. Am J Cardiol. 1998; 82(7): 912-4.

[24.] Haykowsky MJ, Teo KK, Quinney AH, Humen DP, Taylor DA. Effects of long term resistance training on left ventricular morphology. Can J Cardiol. 2000; 16(1): 35-8.

[25]. Haykowsky MJ, Quinney HA, Gillis R, Thompson CR. Left ventricular morphology in junior and master resistance trained athletes. Med Sci Sports Exerc. 2000; 32(2): 349-352.

[26]. Haykowsky M, Humen D, Teo K, Quinney A, Souster M, Bell G, et al. Effect of 16 weeks of resistance training on left ventricular Morphology and systolic function in healthy men (60 years of age). Am J Cardiol.2000; 85(8): 1002-6.

[27]. Barauna VG, Junior ML, CostaRosa LF, Casarini DE, Krieger JE, Oliveira EM. Cardiovascular adaptationsin rats submitted to a resistance-training model. ClinExpPharmacol Physiol. 2005; 32(4): 249-54.

[28.] Levinger I, Bronks R, Cody DV, Linton I, Davie A. The effect of resistance training on left ventricularfunction and structure of patients with chronic heart failure.Int J Cardiol. 2005; 105(2): 159-63.

[29]. Lalande S, Baldi JC. Left ventricular mass in elite Olympic weight lifters.Am J Cardiol. 2007; 100(7): 1177-80.

[30]. Camargo MD, Stein R, Ribeiro JP, Schvartzman PR, Rizzatti MO, SchaanBD. Circuit weight training and cardiac morphology: a trial with magnetic resonance imaging. Br J Sports Med. 2008; 42(2): 141-5.

[31]. D'Andrea A, Limongelli G, Caso P, Sarubbi B, Pietra A.D, Brancaccio P, et al. Association between left ventricular structure and cardiac performance during effort in two morphological forms of athlete's heart. IntJCardiol. 2002; 86(3): $177-84$.

[32]. D'Andrea A, Caso P, Scarafile R, Salerno G, De Corato G, Mita C, et al. Biventricular myocardial adaption to different training protocols in competitive master athletes. Int J Cardiol. 2007; 115(3): 342-9.

[33]. Shephard H. Athlete's heart. Sport Medicine. 1990; 9(4): 199-204.

[34]. Dibello V, Santoro G, Talarico L, DiMuro C, Caputo M, Giorgi D, et al. Left ventricular function during exercise in athletes and in sedentary men. Med Sci Sports Exerc. 1996; 28(2): 190-6.

[35]. Meyer K, Hajric R, Westbrook S, Haag-Wildi S, Holtkamp R, Leyk D, et al. Hemodynamic responses during leg press exercise in patients with chronic congestive heart failure. Am J Cardiol. 1999; 83(11): 1537-43.

[36]. Pu CT, Johnson MT, Forman DE, Hausdorff JM, Roubenoff R, Foldvari M, et al. Randomized trial of progressive resistance training to counteract the myopathy of chronic heart failure. J Appl Physiol. 2001; 90(6): 2341-50.

[37]. Fleck SG, Kramer WJ. Designing resistance training programs, Colorado College, Colorado Springs, USA.ThirdEdition.Champaign, IL, HumanKineties. 2004; P: 214.

[38.] Kurbel S, Zucic D, Vrbanec D, Plestina S. Comparison of BMI and the body mass/body surface ratio: Is BMI a biased tool? CollAntropol. 2008; 32(1): 299-301.

[39.] Mosteller RD. Simplified calculation of body-surface area. N Engl J Med. 1987; 317(17): 1098.

[40]. Sahn DJ, Demaria A, Kisslo J, Weyman A. The committee on M-mode standardization of the American Society of echocardiography results of a survey of echocardiographic measurements. Circulation. 1978; 58(1): $1072-81$.

[41.] Devereux RB, Liebson PR, Horan MJ. Recommendations concerning the use of echocardiography in hypertension and general population research.Hypertnsion. 1987; 9 (2): II97- II104.

[42]. Fleck S.J. Cardiovascular responses to strength training. In: Komi PV, (editor). Strength and power for sport.Oxford: Blackwell science. Olympic Encydopedia of Sports Medician. Volume III: 2003. P 387.

[43]. Effron M.B. Effects of resistance training on left ventricular function. Med SciExerc. 1989; 21(6): 694-7.

[44]. Robergs R, Roberts S. Fundamental Principles of Exercise Physiology: For Fitness, Performance and Health. Boston: McGraw-Hill; illustrated edition. 1999.+

[45]. Martin CE, Shaver JA, Leon DF, Thompson ME, Reddy PF, Leonard JJ. Autonomic mechanisms in hemodynamic responses to isometric exercise. J Clin Invest. 1974; 54(1): 104-15.

[46.] Fredrick CH, Seamus JW, Robert SS, Robert SH, Roger MG, Thomas FM, et al. Effect of high intensity Resistance training o untrained older men. Strength, cardiovascular, and metabolic response.The Journals of Gerontology Series. 2000; 55(7): B336-6.

[47.] Dunstan DW, Puddey IB, Beilin LJ, Burke V, Morton AR, Stanton KG. Effects Of a short-term circuit weight training program on glycaemic control in NIDDM. Diabetes Research and Clinical Practice. 1998; 40(1): 53-61.

[48.] Ishii N. Factors involved in the resistance-exercise stimulus and their relations to muscular hypertrophy. In Nose H and et al. (eds.) Exercise, nutrition and environmental stress. Cooper, MI, USA: 2002.PP. 119-138.

[49.] Ishii N, Madarame H, Odagiri K, Naganuma M, Shinoda K. Circuit training without external load induces hypertrophy in lowerlimb muscles when combined with Moderate venous occlusion. Int. J. Kaatsu Training Res. 2005; 1(1): 24-28.

[50]. Mosher PE, Nash MS, Perry AC, LaPerriere AR, Goldberg RB. Aerobic circuit exercise training: effect on adolescents with well controlled insulin - dependent diabetes mellitus. Arch Phy Med Rehabil. 1998; 79(6): 652 - 657.

[51]. Wilmore JH, Parr RB, Girandola RN, Ward P, Vodak PA, Barstow TJ, and et al. Physiological alterations consequent to circuit weight training. Med Sci Sports. 1978; 10(2): 79-84. 